


\title{
Trust in the Healthcare System and COVID-19 \\ Treatment in the Developing World. Survey and Experimental Evidence from Armenia
}

\author{
Armenak Antinyan \\ Wenlan School of Business, Zhongnan University of Economics and Law; \\ National Research University Higher School of Economics, Moscow \\ Thomas Bassetti \\ Department of Economics 'Marco Fanno', University of Padua \\ Luca Corazzini \\ Ca' Foscari University of Venice; Center for Experimental Research in Management and Economics \\ (CERME) \\ Filippo Pavesi \\ School of Economics and Management, LIUC (Carlo Cattaneo University); \\ Stevens Institute of Technology
}

\begin{abstract}
Concerns are looming that the healthcare systems in low- and middleincome countries (LMICs) are mostly unprepared to combat COVID-19 because of limited resources. The problems in LMICs are exacerbated by the fact that citizens in these countries generally exhibit low trust in the healthcare system, which could trigger a number of uncooperative behaviors.

In this paper, we focus on one such behavior and investigate the relationship between trust in the healthcare system and the likelihood of potential treatment-seeking behavior upon the appearance of the first symptoms of COVID-19. First, we provide motivating evidence from a unique national on-line survey administered in Armenia - a post-Soviet LMIC country. We then present results from a large-scale survey experiment in Armenia that provides causal evidence in support of the investigated relationship. Our main finding is that a more trustworthy healthcare system enhances the likelihood of potential treatment-seeking behavior when observing the initial symptoms.
\end{abstract}

Keywords : COVID-19, Epidemic, Healthcare system, Trust, Survey experiment

JEL Codes: C9, I12, I15

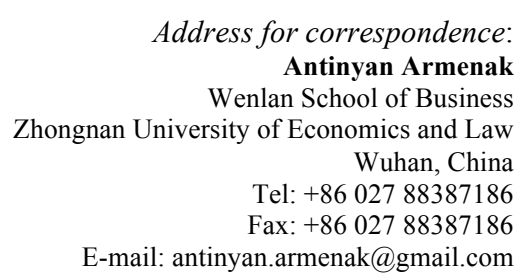

The Working Paper Series is available only on line (http://www.unive.it/pag/16882/) For editorial correspondence, please contact: wp.dse@unive.it
Department of Economics

Ca' Foscari University of Venice

Cannaregio 873, Fondamenta San Giobbe

30121 Venice Italy

Fax: ++390412349210 


\title{
Trust in the Healthcare System and COVID-19 Treatment in the Developing World. Survey and Experimental Evidence from Armenia
}

\author{
Armenak Antinyan, ${ }^{1}$ Thomas Bassetti, ${ }^{2}$ Luca Corazzini, ${ }^{3}$ Filippo Pavesi ${ }^{4}$
}

\begin{abstract}
Concerns are looming that the healthcare systems in low- and middle-income countries (LMICs) are mostly unprepared to combat COVID-19 because of limited resources. The problems in LMICs are exacerbated by the fact that citizens in these countries generally exhibit low trust in the healthcare system, which could trigger a number of uncooperative behaviors.

In this paper, we focus on one such behavior and investigate the relationship between trust in the healthcare system and the likelihood of potential treatment-seeking behavior upon the appearance of the first symptoms of COVID-19. First, we provide motivating evidence from a unique national on-line survey administered in Armenia - a post-Soviet LMIC country. We then present results from a large-scale survey experiment in Armenia that provides causal evidence in support of the investigated relationship. Our main finding is that a more trustworthy healthcare system enhances the likelihood of potential treatment-seeking behavior when observing the initial symptoms.
\end{abstract}

Keywords: COVID-19; Pandemic; Healthcare system; Trust; Survey experiment. JEL Classifications: C9; I12; I15.

\footnotetext{
${ }^{1}$ Corresponding Author. Wenlan School of Business, Zhongnan University of Economics and Law, Nanhu Avenue 182, Wuhan 430073, P.R. China and National Research University Higher School of Economics, Pokrovsky Boulevard 11, Moscow 119049, Russian Federation. E-mail: antinyan.armenak@gmail.com, Tel: +86 027 88387186, Fax: +8602788387186.

${ }^{2}$ University of Padua, Department of Economics and Management "Marco Fanno”, Via del Santo 33, 35123, Padua, Italy. Email: thomas.bassetti@unipd.it.

${ }^{3}$ Department of Economics and Center for Experimental Research in Management and Economics (CERME), University of Venice "Ca’ Foscari," Cannaregio, 821, 30121 Venezia (VE), Italy, and ISLA, Bocconi University, Milan, Italy. Email: luca.corazzini@unive.it.

${ }^{4}$ School of Economics and Management, LIUC (Carlo Cattaneo University), C.so Matteotti, 22, 21053 Castellanza (VA), Italy, and Stevens Institute of Technology, School of Business, Hoboken, NJ, USA. E-mail: fpavesi@liuc.it.
} 


\section{Introduction}

As of May 21, 2020, there are roughly 5.000.000 COVID-19 cases and 330.000 deaths worldwide. Despite excessively promoted precautionary measures to seek medical attention in case of fever, cough, and difficulty of breathing, in many instances, individuals with symptoms avoid contacting health authorities. For example, a recent Gallup study finds that, in the US, one out of every seven adults (14\%) would not seek coronavirus treatment for themselves or a member of their household (Witters, 2020). There have also been repeated reports of people avoiding professional medical care in low- and middle-income countries (LMICs) lately. According to the mayor of Moscow Sergey Sobyanin, as of April 23, roughly two-thirds of the coronavirus victims in Moscow first opted for self-care and then found themselves in the hospitals in critical condition. In India, there have been instances of isolated patients (with either confirmed or suspected COVID19 cases) trying to run away from public hospitals (Chetterje, 2020). While in the US the cost of medical treatment seems to be one of the main factors deterring individuals from seeking medical help (Witters, 2020), the reasons in LMICs can be quite different because in many of these countries the financial burden is born by the public healthcare system and COVID-19 is treated for free. More specifically, in LMICs - e.g., Turkey, South Africa, India, Russia, Chile, Mexico, Colombia, Brazil - the society is plagued with widespread trust deficit in the healthcare system (e.g., Chetterje, 2020; Ipsos, 2018), which can discourage patients with COVID-19 symptoms to seek medical care. The scientific evidence seems to support this conjecture, as there is considerable evidence that social capital - proxied either by trust in the society members or by trust in formal institutions - serves as a viable determinant of health behavior and outcomes (Herian et al., 2014; Rocco et al., 2014; Murray and McCrone, 2015; Hollard and Sene, 2016).

Stemming from the abovementioned discussion, this paper investigates the relationship between the perceived trust in the healthcare system and the likelihood of seeking professional medical help (either calling COVID-19 hotline, or calling an ambulance, or going to hospital) in case of first symptoms of COVID-19 in a LMIC, the Republic of Armenia. We believe that this question is of utmost importance for several reasons.

First, given the absence of effective antiviral treatments for COVID-19 (e.g., Richardson et al., 2020; Russell et al., 2020), the vital option to curb mortality boils down to early and strong interventions to prevent the progression of the disease (e.g., Sun et al., 2020). 
Second, if not treated properly at illness onset, COVID-19 can progress to a severe form. This will lead the patients to need intubation and invasive ventilation in an intensive care unit (ICU), increasing the burden on buckling healthcare systems, considering that the world desperately scrambles for ventilators and ICU beds (Woodyatt, 2020).

Third, a solid number of COVID-19 cases may remain undetected, which can contribute to the exponential transmission of the virus. In this regard, LMICs account for roughly half of the world population, albeit the number of COVID-19 cases and deaths in these countries is unrealistically low in the share of global cases and death toll (Shellekens and Sourrouille, 2020). Recall that rapid diagnosis, immediate isolation of cases, rigorous tracking and precautionary self-isolation of contacts lie at the heart of effectively curtailing the outbreak of the disease (e.g., Ferretti et al., 2020; Salathe et al., 2020).

To investigate the relationship between trust in the healthcare system and the likelihood of seeking medical care in case of first COVID-19 symptoms, we begin by utilizing data from a nationwide on-line survey collected by the Caucasus Research Resource Centers (CRRC) in Armenia from March 29 to April 8, 2020, as motivating evidence. The standardized questionnaire includes seventeen questions about COVID-19 as well as an elicitation of respondents' trust in the healthcare system and their socio-demographic profile. To the best of our knowledge, this is one of the rare large-scale surveys about COVID-19 in LMICs that simultaneously elicits respondents' trust in the healthcare system and their intentions to seek medical help in case of coronavirus symptoms.

As a LMIC country in transition, where around half of the population is dissatisfied with the health system (Footman et al., 2013) and one-quarter of the population does not trust doctors and nurses (Wellcome Global Monitor, 2019), Armenia makes an ideal case for tackling the research question posed. On top of the low trust in the healthcare system, Armenia is characterized by relatively high levels of poverty (23.5\%; Armstat, 2019) and corruption (Gallup, 2019). That being said, the share of Government expenditure devoted to public health in Armenia is lower than the world average (e.g., Lavado et al., 2018), ${ }^{5}$ which implies that the public healthcare system in Armenia is not in good shape to fight COVID-19 once the cases increase. More specifically, the

\footnotetext{
${ }^{5}$ In 2014, the unweighted world average was around $11.8 \%$ as compared to roughly $7 \%$ in Armenia. According to WHO estimates such a stark difference is preserved in subsequent years as well (an interested reader can refer to WHO's Global Health Expenditure Database (http://apps.who.int/nha/database, retrieved on 17.05.2020).
} 
country faces a shortage of ventilators, ICU equipment, personal protective equipment, lab reagents and supplies (Torosyan, 2020). Various international organizations support the country to address the urgent need for equipment and medical supplies. ${ }^{6}$

From a methodological perspective, the survey we utilize only allows us to establish a potential correlation between trust in formal institutions and the likelihood of seeking professional medical help in case of COVID-19 symptoms. To further investigate the causal link between these variables of interest, we therefore ran a nationwide survey experiment in the Republic of Armenia from April 30 to May 1. Using a survey experiment represents an optimal methodological choice for our study. First, it allows us to establish a clear causal relationship between trust and the likelihood of seeking medical care. Second, it offers the possibility to frame the decision task by referring to the COVID-19 context and manipulate the level of trust in the healthcare system. Specifically, in the survey experiment, we present vignettes that depict an agent who lives in a country with high trust or low trust in the healthcare system and develops COVID-19 symptoms. The respondents are requested to advise the agent whether to seek professional medical help or not. In sum, we manipulate the trust in the healthcare system and assess how respondents' recommendations change because of this manipulation. For each vignette, we also introduce a manipulation check to ensure that the vignettes affect the respondents' trust in the healthcare system. More specifically, we provide a description of a more versus less trustworthy healthcare system utilizing the same wording as in the vignette and then allow the subjects to self-report their trust in relation to these descriptions. Thus, even if the study participants relate various unobservable definitions with the concept of trust, we can study how “our” concept of trust relates to their responses. Interested readers can find both the vignettes and the trust manipulation questions in Appendix B.

Anticipating the results, we document a robust relationship between trust in the healthcare system and the likelihood of seeking professional medical help. More specifically, individuals with high trust in the healthcare system are more likely to seek professional help and treatment in case of first coronavirus symptoms. This result holds both for the survey and the survey experiment.

Our results suggest that on top of implementing standard policy responses to curb the contagion such as introducing lockdowns and social distancing measures, as well as making the face masks mandatory, the governments in developing countries may need to enhance the society's trust in

\footnotetext{
${ }^{6}$ See e.g., https://www.worldbank.org/en/news/press-release/2020/04/03/world-bank-supports-armenia-to-combatthe-human-impact-of-the-covid19-pandemic (retrieved on 19.05.2020).
} 
the healthcare systems. Given the financial constraints, policymakers may opt for interventions that increase community monitoring, which empowers patients to hold the frontline staff accountable (Bjorkman and Svensson, 2009; Christensen et al., 2020). Alternatively, policymakers may also try to trigger competition among clinics by introducing key performance indicators and ranking the clinics according to their performance (e.g., Christensen et al., 2020). Lastly, along with interventions to make the frontline more effective, policymakers may want to organize aggressive newspaper, social media and TV campaigns to alter society's negative image of the healthcare system and increase the uptake of the provided services.

The rest of the paper is structured as follows. Section 2 relates the present work with the existing literature. Section 3 sketches the empirical approach. Section 4 describes the survey data, the empirical specification and reports the results of the estimations. Section 5 details the survey experiment, while section 6 concludes the paper and provides policy recommendations.

\section{Literature review}

Our paper is related to three streams of literature.

First, we contribute to the mounting research that explores human behavior and preferences during the COVID-19 pandemic. To this date, scholars have mainly studied social preferences during the pandemic (Branas-Garza et al., 2020), the impact of economic preferences on compliance and perception (Müller and Rau, 2020), people's expectations about the macroeconomy (Dietrich et al., 2020; Li, 2020), citizens’ self-reported compliance and the efficacy of government communication (Barari et al., 2020), citizens' reaction to misinformation (Byrsztyn et al., 2020) and evolution of trust at different stages of the pandemic (Battiston et al., 2020). To the best of our knowledge, no paper has studied the relationship between trust in formal institutions, such as the healthcare system, and the likelihood of seeking professional medical treatment in case of COVID-19 symptoms.

Second, we add to the literature that studies the relationship between social capital, health behavior and outcomes. Though social capital is quite a general notion (see the discussion in Hollard and Sene, 2016), we may distinguish between horizontal (or generalized) trust that captures one's trust in other members of the society, neighbors, or peers and vertical trust, that measures one's confidence or trust in formal institutions (e.g., Fischer and Torgler, 2013). There is robust evidence that horizontal trust is positively related to improved health outcomes 
(D’Hombres et al., 2011; Ronconi et al., 2010; Rocco et al., 2014; Herian et al., 2014) and access to primary health care (e.g., Hollard and Sene, 2016) both in developed and developing countries. In a similar fashion, vertical trust or trust in the healthcare system is shown to be linked to the use of health services, improved health outcomes, and satisfaction with care (Whetten et al., 2006; Murray and McCrone, 2015). We substantially diverge from this stream of research in the sense that we investigate the connection between trust and health behavior (in our case seeking for COVID-19 treatment) during a fast-evolving pandemic that has literally paralyzed the world.

Third, we relate to the literature that discusses trust as an important factor in public compliance during a pandemic. More specifically, during H1N1 pandemic, trust in the official institutions led people to adopt recommended behaviors in Italy (Prati et al., 2011), to express intentions to get vaccinated in Netherlands (van der Weerd et al., 2011) and the US (Quinn et al., 2009) as well as to get vaccinated in Switzerland (Gilles et al., 2011). Differently from this literature, we focus on seeking professional medical treatment in case of highly contagious and fatal disease symptoms. Furthermore, there are important differences between the H1N1 pandemic and COVID-19, which make our context different from the ones studied before. According to official WHO communication COVID-19 is ten times deadlier than H1N1 with rather gloomy fatality forecasts (Wood, 2020). For instance, as of early May 2020, it is predicted that nearly 135,000 Americans will die by August 2020 (World Economic Forum, 2020). In addition, COVID-19 is estimated to be almost twice as contagious as H1N1. More specifically while the reproduction number for H1N1 was around 1.2-1.5 (e.g., Benjamin et al., 2020), the reproduction number for COVID-19 can reach up to 5.7 (e.g., Sache et al., 2020). Finally, during the time of the study no vaccine has been invented yet, unlike the timing of the other studies (e.g., Prati et al., 2010, van der Weered, 2010). Taking the abovementioned points into account, the relationship between trust and healthcare seeking behavior can highly differ across H1N1 and COVID-19 pandemics. Lastly, we focus on a causal relationship between trust and healthcare seeking behavior, while the studies discussed above are mainly correlational.

To conclude, to the best of our knowledge, there is no paper that studies the causal relationship between trust and healthcare-seeking behavior amid a highly contagious pandemic with an exponentially growing death toll and no effective antiviral treatment or vaccine. 


\section{Behavioral Prediction and the Empirical Approach}

Following the findings in the medical research, we strive to test whether high trust in formal institutions, such as the government and the healthcare system, increases the likelihood of seeking professional medical help in case of first COVID-19 symptoms. We expect a higher likelihood of treatment-seeking behavior in a high-trust with respect to a low-trust environment.

To check for a relationship between trust and treatment-seeking behavior, first we utilize a nationwide on-line survey conducted by the Caucasus Research Resource Centers (CRRC). COVID-19 is the focus of the survey and the standardized questionnaire includes seventeen questions about COVID-19, respondents' trust in the healthcare system, and the sociodemographic profile of the respondent.

Since the cross-sectional survey evidence merely allows us to establish a correlation between trust and the likelihood of seeking medical help, we administer a large-scale survey experiment in Armenia and manipulate the perception of trust in a hypothetical healthcare system with ad hoc vignettes.

Vignettes are brief representations of an individual or a social situation, which contain relevant and salient factors for the respondent's decision (e.g., Alexander and Becker, 1978). A crucial advantage of vignette studies is that a vignette can narrow the gap between the study and the real world, mimicking actual decision tasks and situations (Hainmueller et al., 2015). Indeed, this is highly relevant for our setting, in which we strive to manipulate the level of trust in the healthcare system as realistically as possible. To do so, we portray loaded vignettes with either a wellfunctioning or a malfunctioning healthcare system.

Even though survey experiments are a potent instrument for establishing a causal link between trust and the likelihood of potential treatment-seeking behavior during COVID-19, they can trigger critical concerns of external validity. For example, the results may be prone to a hypothetical bias, in the sense that the responses to the hypothetical scenarios may considerably conflict with realworld behavior. Alternatively, the specific wording of the vignettes may bias the results. In this regard, Hainmueller et al. (2015) prove the external validity of survey experiments, illustrating that the causal effects obtained in a vignette study hold in natural experiments. 


\section{Study 1: National Survey}

The on-line survey was circulated through Facebook ads from March 29- April 8, 2020. Even though the study targeted individuals living in the territory of Armenia, it is important to note that the sample is not representative of the Armenian population.

Regarding the situation of the pandemic in Armenia, the government declared the state of emergency on March 16, and the entire population was put on a strict lockdown on March 24 (though there were immense problems with enforcing the lockdown). During the survey administration, the number of confirmed cases increased from 424 on May 29 to 881 on April 8. As of April 8, there were only 9 deaths registered. In case of symptoms individuals are advised to isolate and seek professional medical care. As of May 19, all individuals with suspected and confirmed COVID-19 cases were subject to hospitalization and isolation.

\subsection{Data and Descriptive Statistics}

We estimate a regression equation of the following form:

$$
Y_{i}=\beta_{o}+\beta_{1} \times \text { Trust }_{i}+\beta_{2} \times X_{i}+\varepsilon_{i}
$$

The dependent variable, $Y_{i}$, is individual $i$ 's self-reported first action in case of COVID-19 symptoms elicited through the following survey question: "What would your first action be in case of symptoms resembling those of COVID-19 (fever, cough, sore throat, breathing difficulties, weakness)?” To facilitate the analysis, we group the responses into two categories:

i. Treatment-seeking behavior, if the respondent indicates that she will either call COVID-19 hotline, or call an ambulance, or go to a medical institution, or ask for help from a doctor she knows personally. In this case, the dependent variable $Y_{i}$ equals 1.

ii. Treatment-avoiding behavior, if the respondent indicates that she will either treat herself, or isolate at home and wait for recovery, or do nothing. In this case, the dependent variable $Y_{i}$ equals 0 .

Trust $_{i}$ indicates individual $i$ 's trust in the healthcare system. Specifically, the trust variable is built upon respondents' answer to the question: “Given the State of emergency in Armenia, how much do you trust the following institutions? Rate on a scale from 1 (Completely mistrust) to 5 (Completely trust)." The healthcare system is in the list of institutions the respondents had to state their trust in. 
$X_{i}$ contains variables about the demographic and socio-economic conditions of the respondents, such as age, income, education, gender, working status, and settlement type. Table A1 in Appendix A details the variables under consideration and provides the descriptive statistics of the data. Overall, around $32.4 \%$ of the sample is male. The mean respondents' age is 32.4 years old. Roughly $64.9 \%$ of the respondents have a university education. Given that only $20 \%$ of the population has higher education in Armenia according to the results of 2011 population census (Armstat, 2011), we are dealing with an educated sample. This is not much of a surprise, since educated individuals with high income are usually overrepresented in on-line surveys. Surprisingly, the trust in the healthcare system seems to be quite high during the pandemic in the sample under scrutiny. This may be attributed to the fact that we are dealing with an educated sample that is non-representative of the Armenian population. Regarding the first response to COVID-19 symptoms, only 11.5\% respondents self-report potential treatment-avoiding behavior as a first behavioral response.

\subsection{Results}

Given the binary nature of the dependent variable, we estimate (1) utilizing linear probability and probit models. For probit models, the marginal effects are reported. Since the responses within regions can be somewhat correlated, we cluster the standard errors at the regional level. ${ }^{7}$ Table 1 collects the estimates.

\section{Table 1: Regression results}

\begin{tabular}{|c|c|c|c|c|}
\hline & (1) LPM & (2) LPM & (3) Probit & (4) Probit \\
\hline Trust in healthcare system & $\begin{array}{l}0.019 * * * \\
(0.002)\end{array}$ & $\begin{array}{l}0.019 * * * \\
(0.002)\end{array}$ & $\begin{array}{l}0.018 * * * \\
(0.002)\end{array}$ & $\begin{array}{l}0.017 * * * \\
(0.002)\end{array}$ \\
\hline Male & & $\begin{array}{l}-0.012 \\
(0.007)\end{array}$ & & $\begin{array}{l}-0.012 * \\
(0.007)\end{array}$ \\
\hline Vocational education & & $\begin{array}{l}-0.015 \\
(0.016)\end{array}$ & & $\begin{array}{l}-0.014 \\
(0.016)\end{array}$ \\
\hline $\begin{array}{l}\text { University education } \\
\text { (completed or incomplete) }\end{array}$ & & -0.011 & & -0.011 \\
\hline Medium-income group & & $\begin{array}{c}0.009 \\
(0.009)\end{array}$ & & $\begin{array}{c}0.009 \\
(0.009)\end{array}$ \\
\hline High-income group & & $\begin{array}{c}0.007 \\
(0.015)\end{array}$ & & $\begin{array}{c}0.006 \\
(0.015)\end{array}$ \\
\hline
\end{tabular}

\footnotetext{
${ }^{7}$ We also run regression models in which we account for the potential heteroskedasticity of the residuals by introducing White robust standard errros, instead of clustering the error term. The results are qualitatively identical and available upon request.
} 


\begin{tabular}{|c|c|c|c|c|}
\hline Age & & $\begin{array}{l}-0.002 * * * \\
(0.000)\end{array}$ & & $\begin{array}{l}-0.002 * * * \\
(0.000)\end{array}$ \\
\hline Constant & $\begin{array}{l}0.803^{* * *} \\
(0.011)\end{array}$ & $\begin{array}{l}0.875^{* * *} \\
(0.012)\end{array}$ & & \\
\hline F statistics or Wald- $\chi^{2}$ & 61.480 & 84.885 & 67.965 & 712.578 \\
\hline $\mathrm{R}^{2}$ or pseudo $\mathrm{R}^{2}$ & 0.004 & 0.008 & 0.006 & 0.011 \\
\hline Number of Observations & 6,413 & 6,413 & 6,413 & 6,413 \\
\hline
\end{tabular}

Note: Results from OLS (clustered standard errors in parentheses) and probit (clustered standard errors in parentheses) models. For the probit model marginal effects are reported. Dependent variable: Respondents' self-reported potential action in case of COVID-19 symptoms, which equals 1 if treatment-seeking behavior is suggested and 0 if treatmentavoiding behavior is suggested. Independent Variables: Trust in healthcare system- An integer, indicating respondent's trust in the healthcare system on a scale from 1 (Fully distrust) to 5 (Fully trust); Male- Dummy variable which equals to 1 if the respondent is male and 0 otherwise; Vocational education- Dummy variable which equals 1 if the respondent has vocational education and 0 otherwise; University education- Dummy variable which equals 1 if the respondent has university education (either completed or incomplete) and 0 otherwise; Medium-income groupDummy, which equals 1 if the respondent reports income in the intervals of 575,001-969,000 AMD, and 969,001 or above AMD; Age- An integer, indicating the age of the respondent. Significance levels: ${ }^{*} p<0.1 ;{ }^{* *} p<0.05 ; * * * p<0.01$.

The positive and highly significant coefficient of Trust in healthcare system indicates a positive association between trust in the respective institution and treatment-seeking behavior as a first response to COVID-19 symptoms. One possible interpretation of this correlation is that high trust increases the likelihood of seeking professional medical care. According to this line of reasoning, the more the patient trusts the healthcare system, the more likely she is to opt for care in case of first symptoms of COVID-19. Interestingly, we also detect a significant age effect, whereby the likelihood of reporting treatment-seeking behavior decreases with age.

Result 1: There is a positive relationship between trust in the healthcare system and selfreported treatment-seeking behavior as a first response to COVID-19 symptoms.

\section{Study 2: The Survey Experiment}

\subsection{Design}

To demonstrate the causal impact of trust on the likelihood of treatment-seeking behavior, we administer a survey experiment consisting of High-Trust (HT) and Low-Trust (LT) treatments. In both treatments, individuals are requested to respond to an online questionnaire that consists of two sections. The second section, kept constant across treatments, includes regular questions about the demographic and socio-economic conditions of the respondents. In the first section, we manipulate trust through vignettes, depicting a third person living in a hypothetical country with either low or high trust in the healthcare system. This person exhibits COVID-19 symptoms and must decide between two treatment-seeking actions (either call an ambulance or go to the hospital) and three treatment-avoiding actions (either self-treatment or isolation and waiting for recovery or 
living an ordinary life). The respondents are asked to advise the third person to decide between these five alternatives. The responses to the vignettes constitute our main variable of interest.

Regarding the vignettes, there are a few design issues worth detailing.

First, the trust manipulation stems from the paper by Murray and McCrone (2014), which provides an integrative review of empirical studies on factors promoting the patient-healthcare system (provider) relationship. The paper puts forth a definition of trust that hinges on three qualities: interpersonal and technical competence, moral comportment, and vigilance.

Second, for each vignette, we introduce a trust manipulation question to guarantee that the hypothetical scenarios influence the level of perceived trust in the healthcare system. More specifically, before being presented with the situation of the hypothetical person and advising an action in case of COVID-19 symptoms, each participant is requested to state to what extent should an individual trust a healthcare system, described in the same conditions as in the vignette. This allows us to determine whether our results are inspired by trust (as self-reported in the trust manipulation question), rather than by other unobservable individual beliefs or perceptions. ${ }^{8}$

Third, a hypothetical third person residing in a hypothetical country is described in the vignettes. By using a third person, we aim to liberate the study participants from their own circumstances. We assume that the respondents will apply their own preferences when advising the third person. Projecting the vignettes onto a third person is a common approach in the experimental literature (e.g., Antinyan et al., 2020; Carlsson et al., 2007; Johansson-Stenman et al., 2002).

Fourth, we change the gender in the vignettes to avoid potential interactions between the gender of the third person and the responses of the participants. In 50\% of the cases, randomly selected, the hypothetical third person is a male, while in the remaining $50 \%$ of the cases, the hypothetical third person is a female. Figure 1 depicts the structure of the survey experiment, while Table A1 in Appendix A detail the vignettes and trust manipulation questions.

\footnotetext{
${ }^{8}$ In the survey experiment, the trust manipulation question precedes the vignette. While we cannot exclude the fact that introducing the trust manipulation question could have exerted some (demand) effect on the subsequent COVID19 advice, two experimental features of the design of the questionnaire were explicitly thought to minimize potential response biases. First, the manipulation check and the advice question were put in two separate and consecutive screens of the online questionnaire. This means that (i) the respondent was required to confirm the answer to the manipulation check before being presented with the advice question and (ii) the screen with the advice question contained no reference to the answer to the manipulation check. Second, neither the description in the manipulation check nor the advice vignette referred to the word "trust".
} 


\section{Figure 1: The Structure of the Survey Experiment}

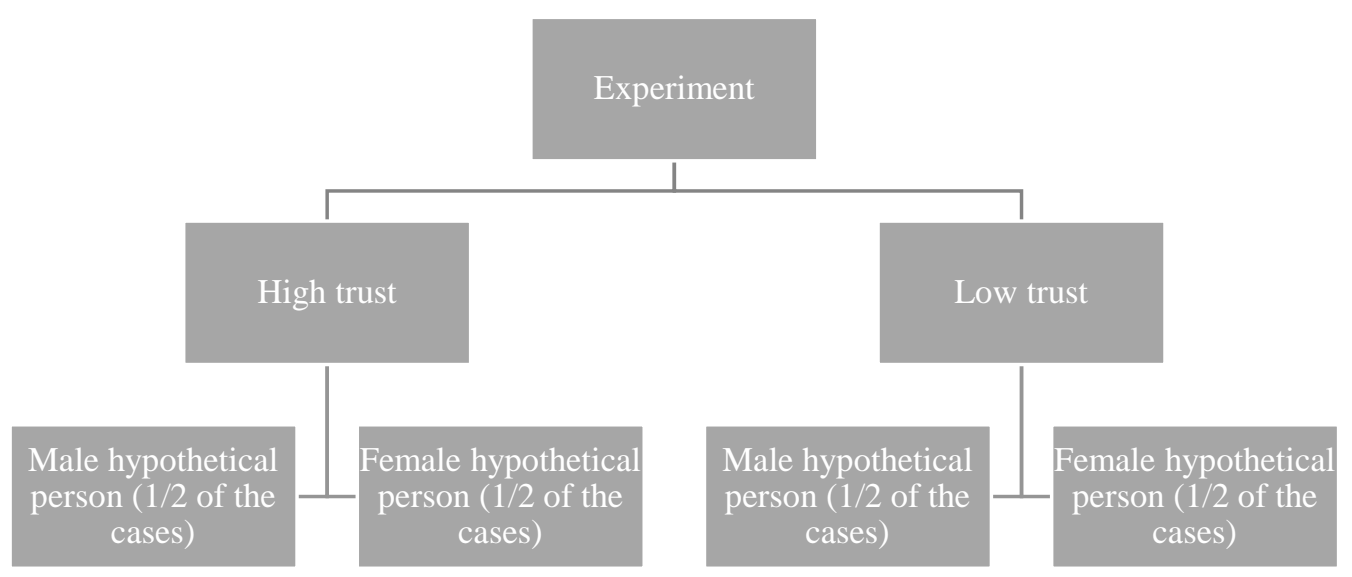

Note: The structure of the survey experiment. The allocation to various treatments and vignettes is randomly determined by the computer.

The survey experiment was again conducted on-line and circulated through Facebook ads from April 30-May 1, 2020. Like the survey, the study targeted individuals living in the territory of Armenia, though the sample is not representative of the Armenian population. As of May 1, there were 2148 confirmed cases and 33 deaths in the country.

\subsection{Results of the Survey Experiment}

In this section, we report the results of the survey experiment. In total, 998 (out of 1,835) respondents completed the questionnaire. We further dropped 34 observations since the respondents indicated residence outside Armenia. Additional 16 observations were dropped because of unrealistic answers to the question about age. In the end, we are left with 948 observations for the statistical analysis. Table A2 in Appendix A depicts the socio-demographic characteristics of the sample. The vignettes are balanced with respect to observable socioeconomic and demographic characteristics. Appendix $\mathrm{C}$ reports the balancing tests.

We first check whether the scenarios described in the questionnaire affect individuals' perceived trust in the health system. To do so, we compare the responses to the trust manipulation questions. According to Figure 2, trust in the healthcare system is considerably higher in the highthan in the low-trust scenario. 


\section{Figure 2: Trust Manipulation in the Experiment}

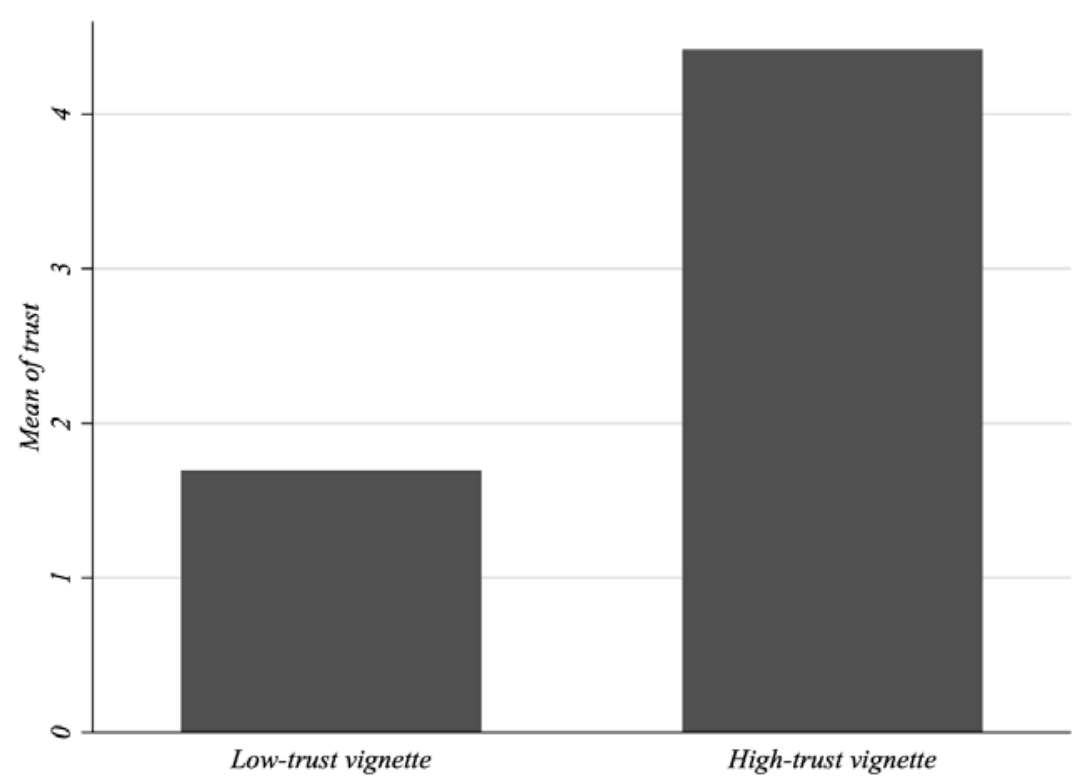

Note: Trust in the health system in the experiment.

The non-parametric Mann-Whitney $U$ test suggests that the differences in trust are statistically significant $(Z=-24.323$, $p$-value=0.000). Thus, the scenarios effectively alter the participants' perceived trust in the healthcare system.

Next, we focus on the first potential actions suggested by participants in case of COVID-19 symptoms, by comparing the responses to the vignettes across treatments. To facilitate the analysis, we group the responses to the vignettes into two categories:

i. Treatment-seeking advice, if the respondent suggests either to go to a medical institution or to call an ambulance;

ii. Treatment-avoiding advice, if the respondent suggests either to isolate at home and treat herself, or to isolate at home and wait for recovery, or to do nothing and live an ordinary life.

Figure 3 reports the frequency of individuals who suggest treatment-avoiding behavior in the high-trust and low-trust vignettes. Remarkably, according to the figure, the frequency of suggested treatment-avoiding advice substantially differs across high trust and low-trust vignettes. 


\section{Figure 3: Frequency of treatment-avoiding advice}

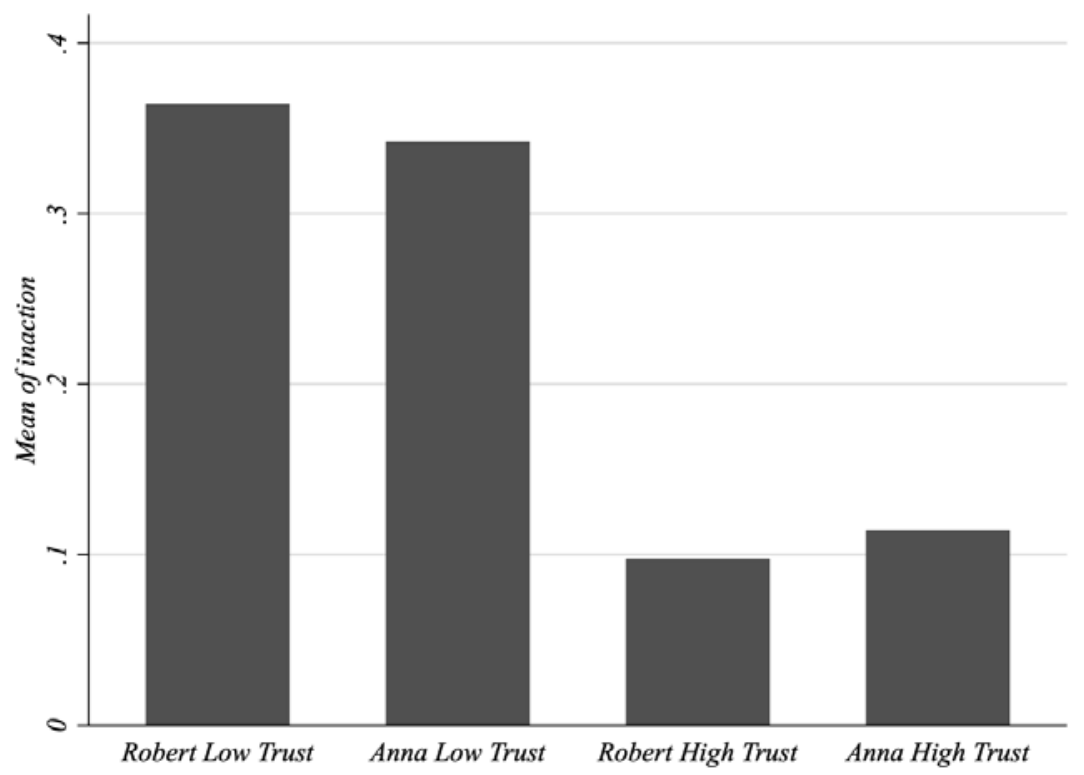

Note: Frequency of treatment-avoiding advice in the vignettes.

To isolate the effect of various determinants - type of the vignette, gender of the vignette, socio-economic and demographic variables — on suggesting treatment-seeking behavior as a first response in case of COVID-19 symptoms we utilize parametric regression techniques. We regress the respondents' suggestions in case of COVID-19 symptoms on a High-Trust dummy, which equals 1 if the vignette refers to the high-trust scenario and to 0 otherwise, as well as on a set of socio-economic and demographic controls (age, income, education, gender, settlement type). We also account for the gender of the third person depicted in the vignettes.

Given the binary nature of our dependent variable, which equals 1 if treatment-seeking behavior is suggested and 0 if treatment-avoiding behavior is suggested, we estimate linear probability and probit models. Since the responses within regions can be somewhat correlated, we cluster the standard errors at the regional level. ${ }^{9}$ Table 2 reports the estimates.

\footnotetext{
${ }^{9}$ We also run regression models in which we account for the potential heteroskedasticity of the residuals by introducing White robust standard errros, instead of clustering the error term. The results remain qualitatively unchanged and available upon request.
} 
Table 2: Results

\begin{tabular}{lcc}
\hline & $(1)$ LPM & $(2)$ Probit \\
\hline High-trust dummy & $0.246^{* * *}$ & $0.246^{* * *}$ \\
& $(0.031)$ & $(0.030)$ \\
Gender of the vignette & -0.002 & 0.000 \\
& $(0.023)$ & $(0.024)$ \\
Male & -0.014 & -0.018 \\
& $(0.028)$ & $(0.028)$ \\
Working & 0.028 & 0.025 \\
& $(0.033)$ & $(0.034)$ \\
Age & -0.001 & -0.001 \\
& $(0.001)$ & $(0.001)$ \\
Income & $-0.011^{* * *}$ & $-0.011^{* * *}$ \\
& $(0.002)$ & $(0.002)$ \\
Education & -0.017 & -0.014 \\
& $(0.014)$ & $(0.015)$ \\
Constant & $0.755^{* * *}$ & \\
\hline F statistics or Wald- $\chi^{2}$ & $(0.050)$ & \\
$\mathrm{R}^{2}$ or pseudo $\mathrm{R}^{2}$ & 138.778 & 942.194 \\
Number of Observations & 0.086 & 0.090 \\
\hline
\end{tabular}

Note: Results from OLS (clustered standard errors in parentheses) and probit (clustered standard errors in parentheses) models. For the probit model marginal effects are reported. Dependent variable: Respondents' suggestion for action in case of COVID-19 symptoms, which equals 1 if treatment-seeking behavior is suggested and 0 if treatment-avoiding behavior is suggested. Independent Variables: High-trust dummy- Dummy variable which equals to 1 in high-trust vignettes and 0 otherwise; Gender of the vignette dummy- Dummy variable which equals to 1 if the gender of the third person in the vignette is male and 0 otherwise; Male- Dummy variable which equals to 1 if the respondent is male and 0 otherwise; Working- Dummy variable which equals to 1 if the respondent is employed either full-time or part-time or self-employed and 0 otherwise; Age- An integer, indicating the age of the respondent; Education- An integer that indicates the highest level of the respondent's education and assumes the values of 1 (No education), 2 (School certificate); 3 (Bachelor's degree); 4 (Master's degree) and 5 (PhD); Income- An integer, indicating the income group the respondents belong to and assumes the values of 1 (up to 24,000 AMD), 2 (24,001-48,000 AMD), 3 (48,001120,000 AMD), 4 (120,001-192,000 AMD), 5 (192,001-384,000 AMD), 6 (384,001-576,000 AMD) and 7 (576,001 AMD and more). Significance levels: $* p<0.1 ; * * p<0.05 ; * * * p<0.01$.

The positive and highly significant coefficient of the High-trust dummy suggests that the probability of advising treatment-seeking behavior as a first reaction to COVID-19 symptoms is considerably higher in the high-trust vignette than in the low-trust vignette.

Result 2. High trust in the health system increases the likelihood of seeking professional medical assistance in case of first symptoms of COVID-19.

\section{Conclusion}

“The growing COVID-19 crisis threatens to disproportionately hit developing countries, not only as a health crisis in the short term but as a devastating social and economic crisis 
over the months and years to come" (UNDP, 2020). Compared to HICs, LMICs start the fight against COVID-19 from a disadvantaged position. First, it is very likely that under-resourced hospitals and fragile health systems will be quickly overwhelmed in these countries. A spike in cases because of lack of access to soap and water may complicate the situation even further in several low-income countries. Second, there is a huge distrust between citizens and formal institutions in LMICs, including the trust citizens exhibit toward the healthcare system. Low trust in formal institutions can induce the citizens to get engaged in a number of uncooperative behaviors, which can severely undermine the efforts the governments exert to stop COVID-19 in LMICs. For instance, in order to contain the spread and the mortality rate, it is crucial that citizens engage in the proper protocols in treating contagious diseases when they develop symptoms. In this regard, the relatively low number of reported cases of COVID-19 in developing countries may in fact be also influenced by the citizens' reluctance to actively engage with the public health system.

In this study, we explored how the degree of distrust in the public health system may play a role in dissuading citizens from actively treating themselves and therefore possibly adopting behavior that can facilitate the spread of contagious diseases, as well as increase the chances of developing more severe symptoms. Our main finding based on causal evidence from a LMIC such as Armenia, suggests that developing countries that have more trusted institutions may therefore be more likely to contain the potentially devastating effects of pandemics. This provides evidence of a previously unexplored channel through which trust in institutions may have a positive effect on welfare.

\section{Acknowledgements}

The article was prepared during Armenak Antinyan's visit to the International Laboratory for Behavioral and Experimental Economics at Higher School of Economics within the framework of the Basic Research Program at the National Research University Higher School of Economics (HSE) and partially supported within the framework of a subsidy by the Russian Academic Excellence Project '5-100.' The Ethical Committee of the Department of Economics, University of Venice “Cà Foscari” approved the experimental protocol. Declarations of interest: none. 


\section{References}

Antinyan, A., Corazzini, L., \& Pavesi, F. (2020). Does trust in the government matter for whistleblowing on tax evaders? Survey and experimental evidence. Journal of Economic Behavior \& Organization, 171, 77-95.

Alexander, C. S., and Becker, H. J. (1978). The use of vignettes in survey research. Public Opinion Quarterly, 42(1), 93-104.

Armstat (2011). The results of the 2011 national census of the Republic of Armenia. National Statistical Service of the Republic of Armenia.

Armstat (2019). Social Snapshot and Poverty in Armenia. National Statistical Service of the Republic of Armenia.

Barari, S., Caria, S., Davola, A., Falco, P., Fetzer, T., Fiorin, S., ... \& Kraft-Todd, G. (2020). Evaluating COVID-19 public health messaging in Italy: Self-reported compliance and growing mental health concerns. medRxiv.

Battiston, P., Kashyap, R., \& Rotondi, V. (2020). Trust in science and experts during the COVID19 outbreak in Italy. OSF Preprints.

Branas-Garza, P., Jorrat, D. A., Alfonso, A., Espin, A. M., García, T., \& Kovarik, J. (2020). Exposure to the Covid-19 pandemic and generosity in southern Spain.

Bursztyn, L., Rao, A., Roth, C., \& Yanagizawa-Drott, D. (2020). Misinformation during a pandemic. University of Chicago, Becker Friedman Institute for Economics Working Paper, (2020-44).

Chetterje, P. (2020). Gaps in India's preparedness for COVID-19 control. The Lancet Infectious Diseases.

Cowling, B. J., Lau, M. S., Ho, L. M., Chuang, S. K., Tsang, T., Liu, S. H., Leung, P. Y., Lo, S. V., \& Lau, E. H. (2010). The effective reproduction number of pandemic influenza: prospective estimation. Epidemiology, 21(6), 842.

Dietrich, A., Keuster, K., Müller, G. J., \& Schoenle, R. (2020). News and uncertainty about covid19: Survey evidence and short-run economic impact.

Ferretti, L., Wymant, C., Kendall, M., Zhao, L., Nurtay, A., Abeler-Dörner, L., Parker, M., Bonsall, D., \& Fraser, C. (2020). Quantifying SARS-CoV-2 transmission suggests epidemic control with digital contact tracing. Science, 368(6491). 
Fischer, J. A., \& Torgler, B. (2013). Do positional concerns destroy social capital: evidence from 26 countries. Economic Inquiry, 51(2), 1542-1565.

Footman, K., Roberts, B., Mills, A., Richardson, E., \& McKee, M. (2013). Public satisfaction as a measure of health system performance: a study of nine countries in the former Soviet Union. Health Policy, 112(1-2), 62-69.

Gallup (2019). Wellcome global monitor. Retrieved from https://wellcome.ac.uk/reports/wellcome-global-monitor/2018 (retrieved on 19.05.2020).

Gilles, I., Bangerter, A., Clémence, A., Green, E. G., Krings, F., Staerklé, C., \& Wagner-Egger, P. (2011). Trust in medical organizations predicts pandemic (H1N1) 2009 vaccination behavior and perceived efficacy of protection measures in the Swiss public. European Journal of Epidemiology, 26(3), 203-210.

Hainmueller, J., Hangartner, D., and Yamamoto, T. (2015). Validating vignette and conjoint survey experiments against real-world behavior. Proceedings of the National Academy of Sciences, 112(8), 2395-2400.

Herian, M. N., Tay, L., Hamm, J. A., \& Diener, E. (2014). Social capital, ideology, and health in the United States. Social Science \& Medicine, 105, 30-37.

Hollard, G., \& Sene, O. (2016). Social capital and access to primary health care in developing countries: Evidence from Sub-Saharan Africa. Journal of Health Economics, 45, 1-11.

d'Hombres, B., Rocco, L., Suhrcke, M., \& McKee, M. (2010). Does social capital determine health? Evidence from eight transition countries. Health Economics, 19(1), 56-74.

Ipsos, M. (2018). Global Views on Healthcare in 2018. Retrieved from https://www.ipsos.com/enbe/global-views-healthcare (retrieved on 17.05.2020).

Johansson-Stenman, O., Carlsson, F., and Daruvala, D. (2002). Measuring future grand parents' preferences for equality and relative standing. The Economic Journal, 112(479), 362-383.

Lavado, R., Hayrapetyan, S., \& Kharazyan, S. (2018). Expansion of the Benefits Package: The Experience of Armenia. Universal Health Care Coverage Series No. 27, World Bank Group, Washington, DC.

Müller, S., \& Rau, H. A. (2020). Economic preferences and compliance in the social stress test of the Corona crisis.

Murray, B., \& McCrone, S. (2015). An integrative review of promoting trust in the patient-primary care provider relationship. Journal of Advanced Nursing, 71(1), 3-23. 
Prati, G., Pietrantoni, L., \& Zani, B. (2011). Compliance with recommendations for pandemic influenza H1N1 2009: the role of trust and personal beliefs. Health Education Research, 26(5), 761-769.

Quinn, S. C., Kumar, S., Freimuth, V. S., Kidwell, K., \& Musa, D. (2009). Public willingness to take a vaccine or drug under Emergency Use Authorization during the 2009 H1N1 pandemic. Biosecurity and Bioterrorism: Biodefense Strategy, Practice, and Science, 7(3), 275290.

Richardson, P., Griffin, I., Tucker, C., Smith, D., Oechsle, O., Phelan, A., \& Stebbing, J. (2020). Baricitinib as potential treatment for 2019-nCoV acute respiratory disease. The Lancet, 395(10223), e30.

Rocco, L., Fumagalli, E., \& Suhrcke, M. (2014). From social capital to health-and back. Health Economics, 23(5), 586-605.

Ronconi, L., Brown, T. T., \& Scheffler, R. M. (2012). Social capital and self-rated health in Argentina. Health Economics, 21(2), 201-208.

Russell, C. D., Millar, J. E., \& Baillie, J. K. (2020). Clinical evidence does not support corticosteroid treatment for 2019-nCoV lung injury. The Lancet, 395(10223), 473-475.

Salathé, M., Althaus, C. L., Neher, R., Stringhini, S., Hodcroft, E., Fellay, J., ... \& Eckerle, I. (2020). COVID-19 epidemic in Switzerland: on the importance of testing, contact tracing and isolation. Swiss Medical Weekly, 150(11-12), w20225.

Sanche, S., Lin, Y. T., Xu, C., Romero-Severson, E., Hengartner, N., \& Ke, R. (2020). High Contagiousness and Rapid Spread of Severe Acute Respiratory Syndrome Coronavirus 2. Emerging Infectious Diseases, 26(7).

Schellekens, P., \& Sourrouille, D. The unreal dichotomy in COVID-19 mortality between highincome and developing countries. Retrieved from https://www.brookings.edu/blog/futuredevelopment/2020/05/05/the-unreal-dichotomy-in-covid-19-mortality-between-high-incomeand-developing-countries/ (retrieved on 17.05.2020).

Sun, Q., Qiu, H., Huang, M., \& Yang, Y. (2020). Lower mortality of COVID-19 by early recognition and intervention: experience from Jiangsu Province. Annals of Intensive Care, 10(1), $1-4$.

Transparency International (2019). Corruption perception index. Retrieved from https://www.transparency.org/en/cpi (retrieved on 17.05.2020). 
Torosyan, A. (2020). COVID-19 preparedness and response: the Case of Armenia. Retrieved from https://apps.who.int/gb/COVID-19/pdf_files/14_05/Armenia.pdf (retrieved on 17.05.2020)

Li, K. K. (2020). How Does the COVID-19 Outbreak Affect People's Expectation about the Macroeconomy? Available at SSRN 3567937.

UNDP (2020). COVID-19: Looming crisis in developing countries threatens to devastate economies and ramp up inequality. Retrieved from https://www.undp.org/content/undp/en/home/news-

centre/news/2020/COVID19_Crisis_in_developing_countries_threatens_devastate_economies.ht $\underline{\mathrm{ml}}$ (retrieved on 19.05.2020).

van der Weerd, W., Timmermans, D. R., Beaujean, D. J., Oudhoff, J., \& van Steenbergen, J. E. (2011). Monitoring the level of government trust, risk perception and intention of the general public to adopt protective measures during the influenza A (H1N1) pandemic in the Netherlands. BMC Public Health, 11(1), 575.

Whetten, K., Leserman, J., Whetten, R., Ostermann, J., Thielman, N., Swartz, M., \& Stangl, D. (2006). Exploring lack of trust in care providers and the government as a barrier to health service use. American Journal of Public Health, 96(4), 716-721.

Witters, D. (2020, May 19). In U.S., 14\% With Likely COVID-19 to Avoid Care Due to Cost. Retrieved from https://news.gallup.com/poll/309224/avoid-care-likely-covid-due-cost.aspx (retrieved on 17.05.2020).

Wood, V (2020). Coronavirus 10 times more deadly than swine flu. Retrieved from https://www.independent.co.uk/news/health/coronavirus-deaths-cases-latest-swine-flu-whoa9462896.html (retrieved on 18.05.2020).

Woodyatt, A. (2020). The world is scrambling to buy ventilators in the Covid-19 pandemic. Retrieved from https://www.cnn.com/2020/04/18/africa/covid-19-ventilator-shortage-intlscli/index.html (retrieved on 17.05.2020).

World Economic Forum (2020). Researchers have doubled the U.S. COVID-19 death forecast, citing eased restrictions. Retrieved from https://www.weforum.org/agenda/2020/05/modeldouble-u-s-covid-19-death-forecast-restrictions/ (retrieved on 18.05.2020) 


\section{Online appendices (not intended for publication)}

\section{A. Descriptive statistics}

\section{Table A1: Variables and Descriptive Statistics}

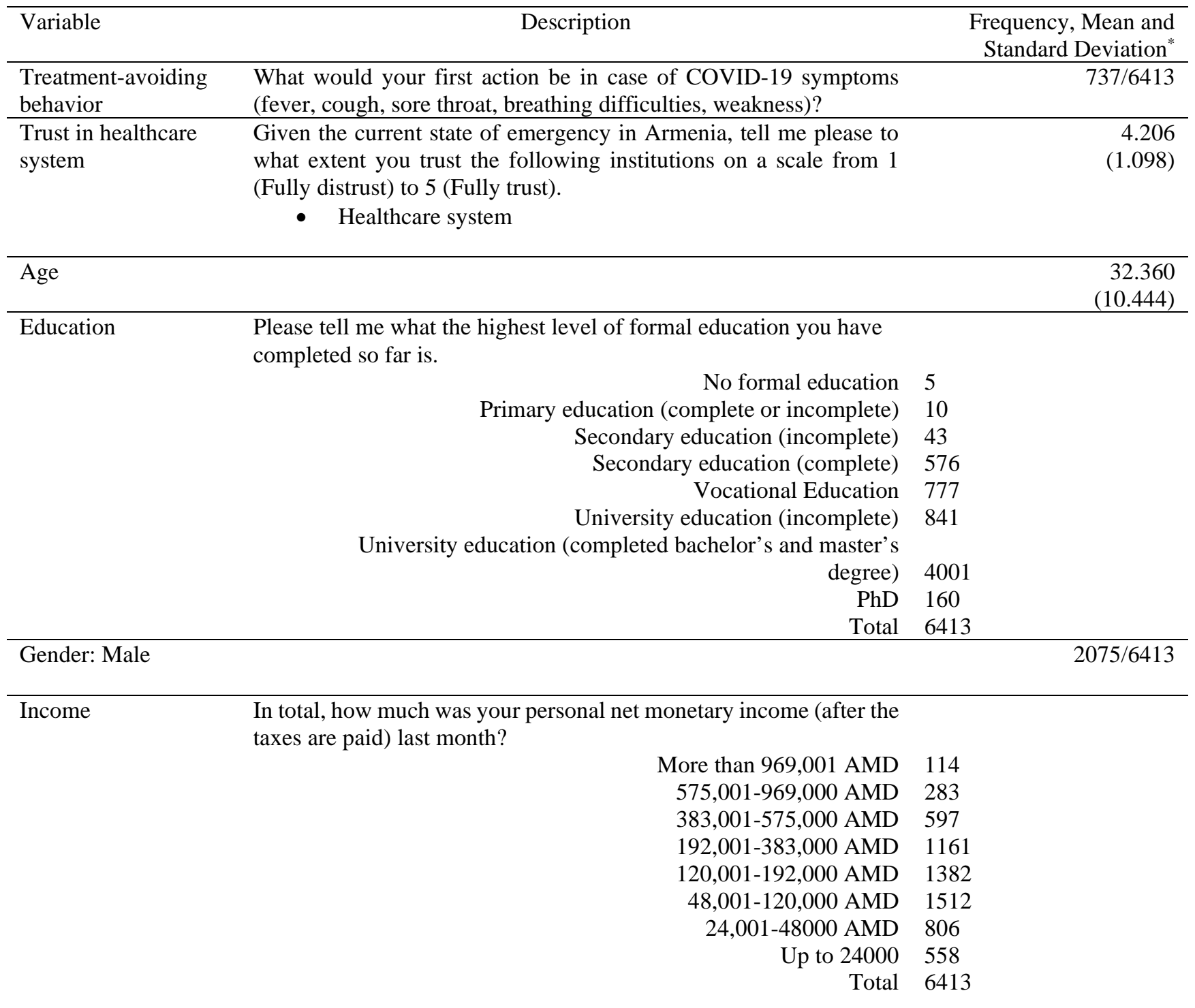

Note: The descriptive statistics of the variables used in the analysis. ${ }^{*}$ In case of First Action, Education, Gender, and Income frequencies are provided. 
Table A2: The Socio-Demographic Characteristics of the Study Participants

\begin{tabular}{lc}
\hline & $(1)$ \\
\hline Mean Age and Standard Deviation & 35.555 \\
& $(12.088)$ \\
Male & 220 \\
& $(23.207 \%)$ \\
Employment Status: Working & 431 \\
Education & $(45.464 \%)$ \\
No education & 12 \\
School Certificate & $(1.266 \%)$ \\
& 251 \\
Bachelor's Degree & $(26.477 \%)$ \\
Master's Degree & 347 \\
& $(36.603 \%)$ \\
PhD & 304 \\
Settlement type & $(32.068 \%)$ \\
Other city & 34 \\
Capital city & $(3.586 \%)$ \\
Village & 334 \\
Income & $(35.232 \%)$ \\
More than 576,001 AMD & 449 \\
384,001-576,000 AMD & $(47.363 \%)$ \\
& 165 \\
192,001-384,000 AMD & $(17.405 \%)$ \\
120,001-192,000 AMD & 88 \\
48,001-121,000 AMD & $(9.282 \%)$ \\
24,001 AMD-48,001 AMD & 56 \\
Up to 24, 000 AMD & $(5.907 \%)$ \\
\hline N & 97 \\
\hline
\end{tabular}

Note: The socio-demographic characteristics of the participants in the survey experiments. 


\section{B. Vignettes}

\section{Table B1: The trust manipulation questions and the vignettes}

Trust manipulation (asked before the low-trust vignette)

Imagine a country in which the healthcare system has the following characteristics:

- Doctors have low competence.

- Many doctors are not empathic to patients' concerns and do not provide any encouragement. These doctors neither listen to the patient nor understand the patient's needs.

- The medical institutions are characterized by long waiting times, and the hygiene standards are low.

- Not all patients in the hospitals are equal: there are certain privileged groups and doctors exhibit friendly attitude to them.

Using a scale from 1 to 5, where ' 1 ' means 'Fully Distrust' and '5' means 'Fully Trust,' please indicate to what extent should a citizen trust the healthcare system of the country described above.

\section{Low-trust vignette}

Imagine Robert [Anna], who lives in Country X. The healthcare system in Country X can be characterized as follows:

- $\quad$ Doctors have low competence.

- Many doctors are not empathic to patients' concerns and do not provide any encouragement. These doctors neither listen to the patient nor understand the patient's needs.

- The medical institutions are characterized by long waiting times, and the hygiene standards are low.

- Not all patients in the hospitals are equal: there are certain privileged groups and doctors exhibit friendly attitude to them.

Robert [Anna] has developed symptoms that resemble those of COVID-19 (coronavirus) symptoms: temperature, tiredness, sore throat, cough. In your opinion, what should Robert's first action be(*)?

- Call emergency

- Visit a medical institution

- Isolate and get engaged in self-care

- Isolate and wait to recover

- Do nothing, live a normal life

*The order of the options presented to the respondents is randomized. 
Trust manipulation (asked before the high-trust vignette)

Imagine a country in which the healthcare system has the following characteristics:

- $\quad$ Doctors have high competence.

- Many doctors are empathic to patients' concerns and always provide encouragement. These doctors always listen to the patient and understand the patient's needs.

- The medical institutions are characterized by short waiting times, and the hygiene standards are high.

- All patients in the hospitals are equal: there are no privileged groups and doctors exhibit friendly attitude to everyone.

Using a scale from 1 to 5, where ' 1 ' means 'Fully Distrust' and '5' means 'Fully Trust,' please indicate to what extent should a citizen trust the healthcare system of the country described above.

\section{High-trust vignette}

Imagine Robert [Anna], who lives in Country X. The healthcare system in Country X can be characterized as follows:

- Doctors have high competence.

- Many doctors are empathic to patients’ concerns and always provide encouragement. These doctors always listen to the patient and understand the patient's needs.

- The medical institutions are characterized by short waiting times, and the hygiene standards are high.

- All patients in the hospitals are equal: there are no privileged groups and doctors exhibit friendly attitude to everyone.

Robert [Anna] has developed symptoms that resemble those of COVID-19 (coronavirus) symptoms: temperature, tiredness, sore throat, cough. In your opinion, what should Robert's first action be $(*)$ ?

- $\quad$ Call emergency

- Visit a medical institution

- Isolate and get engaged in self-care

- Isolate and wait to recover

- Do nothing, live a normal life

*The order of the options presented to the respondents is randomized.

Note: The vignettes used in the survey experiment. In the vignette, where the portrayed third person is female, Anna is replaced with a male character. 


\section{Balancing tests}

Table C1: Balancing Tests

\begin{tabular}{lcccrr}
\hline & Age & $\begin{array}{c}\text { Working } \\
\text { status }\end{array}$ & $\begin{array}{c}\text { Low-income } \\
\text { group }\end{array}$ & $\begin{array}{c}\text { School } \\
\text { education }\end{array}$ & Gender \\
\hline Anna low- trust vignette & 0.792 & 0.004 & -0.123 & 0.083 & -0.026 \\
& $(1.163)$ & $(0.047)$ & $(0.182)$ & $(0.084)$ & $(0.041)$ \\
Robert high- trust vignette & 1.085 & 0.002 & $-0.301^{*}$ & 0.127 & -0.053 \\
& $(1.076)$ & $(0.045)$ & $(0.176)$ & $(0.081)$ & $(0.039)$ \\
Robert low-trust vitnette & -0.406 & 0.040 & -0.059 & $0.139^{*}$ & $-0.077^{* *}$ \\
& $(1.075)$ & $(0.046)$ & $(0.179)$ & $(0.083)$ & $(0.039)$ \\
Constant & $35.173^{* * *}$ & $0.443^{* * *}$ & $3.355^{* * *}$ & $3.013^{* * *}$ & $0.272^{* * *}$ \\
& $(0.770)$ & $(0.033)$ & $(0.130)$ & $(0.061)$ & $(0.030)$ \\
F statistics & 0.812 & 0.341 & 1.140 & 1.153 & 1.449 \\
$R^{2}$ & 0.002 & 0.001 & 0.004 & 0.004 & 0.005 \\
Number of Observations & 948 & 948 & 948 & 948 & 948 \\
\hline
\end{tabular}

* $p<0.1$; ** $p<0.05 ; * * * p<0.01$ 